\title{
The impact of histopathological celiac disease activity on dental enamel defects and dental caries
}

\author{
Zainab Qasim M. Al-Obaidi (1), Nada Jafer M.H. Radhi (2)
}

\begin{abstract}
Background: Celiac disease is an autoimmune chronic disease that affects the human's intestine and subsequently reflects its effect on the entire body health by retardation the absorption and immune mediated complications cause the involvement of oral health. The present study intended to evaluate the impact of the histopathological disease activity upon dental enamel defects and dental caries.

Subjects and methods: Forty celiac-diseased patients aged 7-11 years were collected from 3 different teaching hospitals in Baghdad classified by means of the histopathological activity of the intestinal disease according to modified Marsh-Rostami classification. Dental enamel defects were measured by Aine's classification, while dental caries experience and severity were

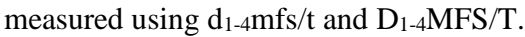

Results: The majority of the sample came with partial villous atrophy of the small intestine (Marsh III-a) and almost half of the sample were with no celiac disease specific dental enamel defects (Aine's 0), while Aine's I was the most predominant than Aine's II. Most missed surfaces due to dental caries in permanent teeth came with Marsh II.

Conclusion: The more the severity of celiac disease histopathological activity the more the severity of celiac specific dental enamel defects and the less experienced dental caries.
\end{abstract}

Key words: Celiac disease, histopathological activity, dental enamel defects, dental caries. (Received: 10/10/2019; Accepted: 13/11/2019)

\section{INTRODUCTION}

Celiac disease $(\mathrm{CD})$ is a chronic hereditary autoimmune inflammatory disease leading to intestinal damage and malabsorption associated with serious health consequences. ${ }^{(1)} \mathrm{CD}$ can introduce itself by multiple signs and symptoms starting from diarrhea, weight loss and abdominal pain to extra-intestinal manifestations including dental enamel defects DED..$^{(2,3)}$ The only available and acceptable treatment is lifelong strict gluten free diet GFD. ${ }^{(1)}$

Endoscopy for CD diagnosis doesn't provide definitive image for intestinal pathology ${ }^{(4)}$ during which multiple biopsies are taken from different sites of the small intestine usually duodenum to submit them for histopathological assay. ${ }^{(5)}$ Small intestine has a major role in digestion, secretion and absorption; numerous mucosal folds containing villi increase the surface area of absorption and digestive enzymes production. ${ }^{(6)}$ Histological features of the duodenal disease are villous atrophy, crypt hyperplasia, increase a number of intraepithelial lymphocytes and decrease in height of enterocytes. ${ }^{(7)}$

(1) Master Student, Department of Pedodontics and Preventive Dentistry, College of Dentistry University of Baghdad.

(2) Assist. Prof. Department of Pedodontics and Preventive Dentistry, College of Dentistry University of Baghdad.
Intestinal epithelial damage is caused by both innate and adaptive immune responses and that intraepithelial lymphocytes, those are elicited by the inflammation caused by gluten and mediated genetically and production of variant immunoglobulin such as tissue transglutaminase, anti-endomesial and anti-gliadin. ${ }^{(8)}$ Modified Marsh-Rostami index had been developed to describe intestinal mucosal damage. ${ }^{(9)}$ Orally, dental enamel defects DED can be identified in some CD patients and this plays a vital role for dentists to play pointing to the disease for diagnosis. ${ }^{(10)}$ When any impaired function of the ameloblasts occurred due to environmental or nutritional deficiency factors, enamel formation would get impaired too. ${ }^{(11)}$

A study by Abdul-Wahid et al ${ }^{(12)}$ revealed an increase in the presence of unspecific dental enamel defects by the application of the Modified Developmental Defects of Enamel Index for 102 CD patients aged 2-35 years compared to the control group in primary and permanent dentitions while dental caries was experienced at higher extent in the primary teeth only.

Higher DED in CD children was observed as compared to children devoid from the disease $(10,13,14)$ in contrast to dental caries that was experienced at lesser extent in CD children. ${ }^{(13)}$ Another study showed no significant difference in prevalence of DED between CD children and others without the disease. ${ }^{(15,16)}$ Another study reported no significant difference in caries experience in $\mathrm{CD}$ children. ${ }^{(16)}$ 
The aim of the current study was the estimation of the essential role that the oral cavity plays as a gate of the gastrointestinal tract at which the health of each may logically affects the other's, thus CD was studied in children with mixed dentition to evaluate $\mathrm{CD}$ histopathological activity impact on DED and dental caries.

\section{SUBJECTS AND METHODS}

Ethical approval was gained from the Ethical Committee of College of Dentistry/University of Baghdad and consents forms were gained from the patients' parents to be included. The sample of the present study consisted of 40 celiac-diseased (CD) children aged 7-11 years according to the last birthday and date of examination, half of them had been just diagnosed and the rest was committed to gluten free diet. Patients should have been devoid from any other diseases. The study was carried out from November 2018 to March 2019. Patients had been collected from pediatric consultation sections of the gastroenterology of three different teaching hospitals in Baghdad.

The disease had been diagnosed according to the European society of pediatric gastroenterology, hepatology and nutrition guidelines (17) histopathological findings were collected from the patients' medical reports by means of grading according to Modified Marsh index for histological CD activity. ${ }^{(9)}$ All histopathological examinations of all patients included were accomplished in the histology laboratory of Gastroenterology and Hepatology Teaching Hospital/Baghdad. Oral examination had been carried out following the basic principles of WHO (1997). ${ }^{(18)}$ Dental enamel defects (DED) had been evaluated descriptively by Aine's classification for CD specific dental enamel defects criteria ${ }^{(10)}$ as shown in table (1); those should have been distributed symmetrically and chronologically in all dental arches when all teeth were examined in all dental quadrants. Dental caries dmfs/t and DMFS/T and severity $D_{1-4} / \mathrm{d}_{1-4}$ were examined and recorded according to Muhlemann. ${ }^{(19)}$ Descriptive statistics was applied, level of significance was set at 0.05 by SPSS program version 21 .
Table 1: Aine's criteria for celiac disease specific dental enamel defects.

\begin{tabular}{|l|l|}
\hline Grade & Description \\
\hline O & No defects meet the criteria \\
\hline II & $\begin{array}{l}\text { Defect in color of enamel. Single or } \\
\text { multiple creamy, yellow or brown } \\
\text { opacities with clearly defined or diffuse } \\
\text { margins; in addition a part or the entire } \\
\text { surface of enamel is without glaze. }\end{array}$ \\
\hline $\begin{array}{l}\text { Slight structural defects, Enamel } \\
\text { surface rough, filled with horizontal } \\
\text { grooves or shallow pits; light opacities } \\
\text { and discoloration may be found; in } \\
\text { addition a part or the entire surface of } \\
\text { enamel is without glaze. }\end{array}$ \\
\hline III & $\begin{array}{l}\text { Evident structural defects, A part or the } \\
\text { entire surface of enamel rough and filled } \\
\text { with deep horizontal grooves which vary } \\
\text { in width or have large vertical pits; large } \\
\text { opacities of different colors or strong } \\
\text { discoloration may be in combination. }\end{array}$ \\
\hline IV & $\begin{array}{l}\text { Severe structural defects, the shape of } \\
\text { the tooth changed: the tips of cusps } \\
\text { are sharp-pointed and/or the incisal } \\
\text { edges are unevenly thinned and } \\
\text { rough; the thinning of the enamel } \\
\text { material is easily detectable and the } \\
\text { margins of the lesions are well } \\
\text { defined; the lesion may be strongly } \\
\text { discolored. }\end{array}$ \\
\hline
\end{tabular}

\section{RESULTS}

The sample contained 22 boys and 18 girls, there was no significant difference concerning gender among the groups (Chi- square $=3.671 ; \mathrm{p}=$ 0.160 ) and the sample had been considered as one age group.

Grading of CD histopathological activity of the current sample revealed that it was devoid from Marsh I and Marsh III-c while Marsh II, III-a and III-b were presented as $3(7.50 \%), 25(62.50 \%)$ and $12(30.00 \%)$ respectively

Aine's classification of dental enamel defects (DED) specific for $\mathrm{CD}$ that was used in the present sample revealed that $19(47.5 \%)$ of children were with no defects (grade 0 ) followed by $17(42.5 \%)$ children with grade I and $4(10 \%)$ children with grade II. Neither Aine's III nor Ain's IV had been found in the present sample Marsh grading of histopathological disease activity in relation to Aine's grading of $C D$ specific dental enamel defects revealed a significant difference among the present grades where there were no enamel defects in Marsh II. On the other hand, the least children with Aine's 0 grades were observed in Marsh III b in contrast to Aine's II enamel defects which were the most frequent in Marsh III-b category (Table 2).

Caries severity and experience were found in $\mathrm{D}_{4}$, DS and DMFS components among Marsh II as compared to Marsh III-a and III-b but no 
significant difference was observed; the same is applied to ds component concerning primary teeth (Table 3).

Multiple comparisons by Games-Howell as ANOVA post hoc test were applied to MS according to the available three Marsh grades showing no significant difference between Marsh III-a and Marsh III-b mean differences $(\mathrm{P}>0.05)$ while high significant differences concerning Marsh II mean difference with both Marsh III-a and III-b $(\mathrm{P}<0.01)$ was noticeable (Table 4). Dental caries experience and severity showed no significant difference in relation to $\mathrm{CD}$ dental enamel defects but the mean values of $\mathrm{d}_{4}$, ds, $\mathrm{dmfs}$ and $\mathrm{dmft}$ for deciduous teeth showed lower results in Aine's II than both Aine's I and Aine's 0. The same was applied to D4 and DS for permanent teeth as shown in table (5) but no statistical differences were found.

Table 2: Celiac disease dental enamel defects according to Aine's classification in relation to the histopathological disease activity measured by modified Marsh-Rostami classification.

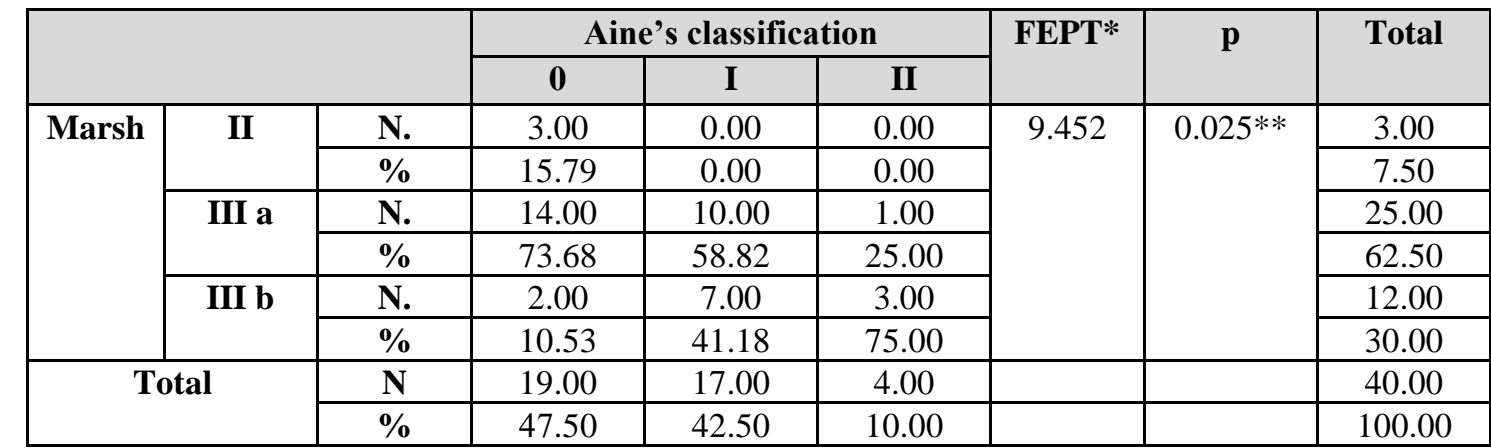

*Fissure Exact Probability Test $\quad$ **Significant $<0.05$

Table 3: Dental caries experience and severity for primary and permanent teeth according to Marsh grading

\begin{tabular}{|c|c|c|c|c|c|c|c|c|}
\hline \multirow{2}{*}{ Dental caries } & \multicolumn{7}{|c|}{ Marsh grading } \\
\cline { 2 - 10 } & \multicolumn{2}{|c|}{ II } & \multicolumn{2}{|c|}{ III-a } & \multicolumn{2}{c|}{ III-b } & \multicolumn{1}{c|}{ F } & p \\
\cline { 2 - 10 } & Mean & SE & Mean & SE & Mean & SE & & \\
\hline d1 & 0.333 & 0.333 & 0.080 & 0.080 & 0.000 & 0.000 & 1.102 & 0.343 \\
\hline d2 & 1.333 & 1.333 & 0.240 & 0.166 & 0.917 & 0.434 & 2.069 & 0.141 \\
\hline d3 & 1.333 & 1.333 & 1.480 & 0.361 & 1.500 & 0.469 & 0.011 & 0.989 \\
\hline ds & 6.333 & 6.333 & 6.040 & 1.498 & 5.667 & 1.676 & 0.015 & 0.985 \\
\hline mS & 9.333 & 9.333 & 7.840 & 1.520 & 7.750 & 1.670 & 0.053 & 0.949 \\
\hline fs & 0.000 & 0.000 & 1.400 & 0.614 & 2.083 & 1.145 & 0.514 & 0.602 \\
\hline dmfs & 0.000 & 0.000 & 0.000 & 0.000 & 0.167 & 0.167 & 1.177 & 0.319 \\
\hline D1 & 9.333 & 9.333 & 9.160 & 1.785 & 10.000 & 2.514 & 0.033 & 0.968 \\
\hline D2 & 5.333 & 5.333 & 5.080 & 0.848 & 5.667 & 0.956 & 0.072 & 0.931 \\
\hline D3 & 0.667 & 0.667 & 1.520 & 0.289 & 1.167 & 0.241 & 0.772 & 0.470 \\
\hline D4 & 0.000 & 0.000 & 0.880 & 0.211 & 1.250 & 0.446 & 1.359 & 0.269 \\
\hline DS & 2.000 & 0.000 & 1.200 & 0.294 & 0.750 & 0.179 & 1.357 & 0.270 \\
\hline MS & 4.333 & 2.603 & 1.600 & 0.408 & 1.417 & 0.645 & 2.073 & 0.140 \\
\hline FS & 0.000 & 0.000 & 0.040 & 0.040 & 0.833 & 0.833 & 1.068 & 0.354 \\
\hline DMFS & 10.333 & 5.364 & 5.000 & 0.648 & 5.417 & 1.171 & 2.334 & 0.111 \\
\hline & 4.667 & 0.667 & 4.440 & 0.597 & 4.417 & 0.733 & 0.010 & 0.990 \\
\hline
\end{tabular}


Table 4: Multiple comparisons of missing component (MS)of DMFS among the three available Marsh grades.

\begin{tabular}{|c|c|c|c|}
\hline \multicolumn{4}{|c|}{ Games-Howell test for MS among Marsh grades } \\
\hline (I) Marsh & (J) Marsh & Mean Difference (I-J) & P \\
\hline \multirow{2}{*}{ III-a } & III-b & 0.00000 & 1.000 \\
\cline { 2 - 4 } & II & -3.33333 & $0.002^{* *}$ \\
\hline III-b & II & -3.33333 & $0.003^{* *}$ \\
\hline
\end{tabular}

** Highly significant $<0.01$

Table 5: Dental caries experience and severity in primary and permanent teeth in relation to Aine's grades of celiac disease enamel defects.

\begin{tabular}{|c|c|c|c|c|c|c|c|c|}
\hline Aine's grade & \multicolumn{2}{|c|}{$\mathbf{0 . 0 0}$} & \multicolumn{2}{c|}{$\mathbf{1 . 0 0}$} & \multicolumn{2}{c|}{$\mathbf{2 . 0 0}$} & \multirow{2}{*}{ F } & \multirow{2}{*}{ P } \\
\hline Dental caries & Mean & SE & Mean & SE & Mean & SE & 0.247 & 0.782 \\
\hline $\mathbf{d}_{1}$ & 0.053 & 0.053 & 0.118 & 0.118 & 0.000 & 0.000 & 0.247 \\
\hline $\mathbf{d}_{2}$ & 0.684 & 0.375 & 0.412 & 0.173 & 0.250 & 0.250 & 0.325 & 0.724 \\
\hline $\mathbf{d}_{3}$ & 1.211 & 0.347 & 1.647 & 0.428 & 2.000 & 1.414 & 0.472 & 0.627 \\
\hline $\mathbf{d}_{4}$ & 5.895 & 1.629 & 6.882 & 1.857 & 2.250 & 1.931 & 0.681 & 0.512 \\
\hline $\mathbf{d s}$ & 7.842 & 1.794 & 8.824 & 1.954 & 4.500 & 2.630 & 0.506 & 0.607 \\
\hline ms & 1.053 & 0.614 & 2.059 & 0.964 & 1.250 & 1.250 & 0.432 & 0.652 \\
\hline fs & 0.000 & 0.000 & 0.118 & 0.118 & 0.000 & 0.000 & 0.665 & 0.520 \\
\hline dmfs & 8.789 & 1.907 & 11.00 & 2.565 & 5.750 & 3.376 & 0.606 & 0.551 \\
\hline dmft & 5.053 & 0.966 & 5.824 & 1.102 & 4.000 & 2.309 & 0.326 & 0.724 \\
\hline $\mathbf{D}_{\mathbf{1}}$ & 1.421 & 0.299 & 1.353 & 0.331 & 1.000 & 0.408 & 0.173 & 0.841 \\
\hline $\mathbf{D}_{2}$ & 0.789 & 0.237 & 1.059 & 0.337 & 1.000 & 0.707 & 0.223 & 0.801 \\
\hline $\mathbf{D}_{3}$ & 1.263 & 0.285 & 1.118 & 0.331 & 0.500 & 0.289 & 0.610 & 0.549 \\
\hline $\mathbf{D}_{4}$ & 2.263 & 0.675 & 1.353 & 0.383 & 1.000 & 1.000 & 0.885 & 0.421 \\
\hline DS & 5.053 & 0.664 & 4.882 & 0.701 & 3.500 & 1.555 & 0.475 & 0.625 \\
\hline MS & 0.526 & 0.526 & 0.000 & 0.000 & 0.000 & 0.000 & 0.540 & 0.588 \\
\hline FS & 0.053 & 0.053 & 0.000 & 0.000 & 2.500 & 2.500 & 4.363 & 0.113 \\
\hline DMFS & 6.000 & 1.084 & 4.882 & 0.701 & 6.000 & 3.342 & 0.337 & 0.716 \\
\hline DMFT & 4.737 & 0.606 & 4.235 & 0.662 & 4.000 & 1.826 & 0.205 & 0.815 \\
\hline
\end{tabular}

\section{DISCUSION}

Celiac disease (CD) had been proved to be accompanied by several systemic and dental defects. Dental enamel defects (DED) are permanent and won't be corrected after gluten free diet (GFD). Early diagnosis of CD patients by dentists can be performed by DED since most CD patients are atypical. ${ }^{(14,20)}$ In the present study almost half of the sample had no CD specific enamel defects, however, most of the defects were enamel opacities (Aine's I). This comes in agreement with a study by Shahraki et al when studying wider range of sample age (3-16 years) and larger sample size (65) of CD patients. ${ }^{(14)}$ Structural abnormalities were also present at lesser extent as Aine's II was in $10 \%$ of the sample which contained no Ain's III or IV and this comes in an agreement with a Turkish study that reported no Aine's III or IV in $60 \mathrm{CD}$ patients' ages 6-16 years. ${ }^{(21)}$ The present study revealed that the least intestinal damage (Marsh II) came with no CD specific DED while the more intestinal damage (Marsh III-a and III-b) came with more $\mathrm{CD}$ specific DED and this comes in contrast with what Aine et al showed by studying adults enamel defects in relation to the degree of histological damage although children cannot be compared to adults. ${ }^{(22)}$

Yet, no specific mechanism was established explaining DED in CD patients; ${ }^{(23)}$ nutritional deficiency specially hypocalcemia and a normal serum concentration of calcium had been found during diagnosis of $\mathrm{CD}$ children, ${ }^{(13)}$ immune mediated as the primary causative factor ${ }^{(25,26)}$ and DED as a hereditary condition and/or affected by environmental circumstances. ${ }^{(24)}$ Dental caries is one of the most mentioned infectious diseases human beings suffer from. ${ }^{(27)}$ An Iraqi study illustrated an increased salivary $\operatorname{IgA}$ in caries free children as compared to caries active in the same age group of the present study ${ }^{(28)}$ while another Iraqi study illustrated an important protective roles of salivary immunoglobulins especially $\operatorname{IgA}$ and IgM against dental caries in normal kindergarten children, ${ }^{(29)}$ since $\mathrm{CD}$ is an autoimmune disease that salivary immunoglobulins are logically suspected to be 
elevated and dental caries was, in the present study, experienced at lesser extent in a more severe intestinal damage and saliva by itself can be used non-invasively to mirror blood. ${ }^{(30)}$ It is wise to investigate salivary immunoglobulins seeking for dental caries protective factors in $C D$ children since patients with increased DED had decreased dental caries. ${ }^{(21)}$

The present study has arrived at the conclusion that the more the severity of the intestinal mucosal damages in $\mathrm{CD}$ children the more the presence of specific dental enamel defects, although no severe enamel defects or intestinal damage was recorded and less extracted permanent teeth due to dental caries in the more intestinal villous atrophy cases as compared to the mild ones.

\section{REFERENCES}

1. Parzanese I, Qehajaj D, Patrinicola F, Aralica M, Chiriva-Internati M, Stifter S, et al. Celiac disease: from pathophysiology to treatment. WJPG. 2017;8:27-38.

2. Allue I. Celiac Disease in Children; Rodrigo, L. and Pena, A. (ed). Celiac Disease and Non-celiac Gluten Sensitivity. Omnia Publisher, 2014. SL:Spain.

3. Jericho H, Guandalini S. Extra-Intestinal Manifestation of Celiac Disease in Children. Nutrients. 2018;10:755.

4. Bai J, Zeballos, E, Fried, M, et al. Celiac disease, WGO practice guidelines. Arab J Gastroenterol. 2007;8:59-67.

5. Mills J, Murray J. Contemporary celiac disease diagnosis: is a biopsy avoidable? Curr Opin Gastroenterol. 2016;32:80-85.

6. Gelberg HB. Normal Digestive Tract Functional Anatomy and Physiology. Toxicol Pathol. 2014;42:54-66.

7. Veress B, Franzén L, Bodin L, Borch K. Duodenal intraepithelial lymphocyte-count revisited. Scand J Gastroenterol. 2004;39:138-144.

8. Tang F, Chen Z, Ciszewski C, et al. Cytosolic PLA2 is required for CTL-mediated immunopathology of celiac disease via NKG2D and IL-15. J Exp Med. 2009;206:707-19.

9. Rostami K, Kerchaert J, von Blomberg B, et al. SAT and serology in adult coeliac, eronegative coeliac disease seems a reality. Neth J Med. 1998;53:15-19. Cited in: Hindruckx P, Levesque B, Holvoet, T. et al. Disease activity indices in coeliac disease: systematic review recommendations for clinical trials. Gut. 2018;67:61-69.

10. Aine L. Dental enamel defects and dental maturity in children and adolescents with coeliac disease. Proc. Finn. Dent. Soc. 1986;82 (Suppl. 3). Cited in: Aine L, Collin P, Keyrinen O. Dental enamel defects in celiac disease. J Oral Pathol Med. 1990;19:241-245.

11. Lunardelli E, Peres A. Prevalence and distribution of developmental enamel defects in the primary dentition of preschool children. Braz Oral Res. 2005;19:144-149.

12. Abdul-Wahid S, Al-Azawi L, Ibrahim I. Enamel defects and malocclusion in patients with celiac disease. J Bagh Coll Dent. 2005;17:98-100.
13. Avşar A, Kalayc A. The presence and distribution of dental enamel defects and caries in children with celiac disease. Turk J Ped. 2008;50:45-50.

14. Shahraki T, Omrani-Mehr S, Hill I Shahraki MA. Comparison of the prevalence of dental enamel defects and other oral findings in children with and without celiac disease. Iran J Pediatr. 2019;29:e64353.

15. Procaccini M, Campisi G, Bufo P, Compilato D, Massaccesi C,Catassi C, Muzio L. Lack of association between celiac disease and dental enamel hypoplasia in a case-control study from an Italian central region. Head Face Med. 2007;3:2.

16. Shteyer E, Berson T, Lachmanovitz O, Hidas A, Wilschanski M,Menachem, et al. Oral Health Status and Salivary Properties in Relation to Gluten-free Diet in Children with Celiac Disease. JPGN. 2013;57:49-52.

17. Husby S, Koletzko S, Korponay-Szabó IR, Mearin ML, Phillips A, Shamir R, Troncone R. et al. European Society for Pediatric Gastroenterology, Hepatology, and Nutrition guidelines for the diagnosis of coeliac disease. J Pediatr Gastroenterol Nutr. 2012;54:136-160.

18. WHO. Basic survey methods. $5^{\text {th }}$ Ed., 1997.

19. Muhlemann, H. Introduction to oral preventive medicine. Quintessenze. 1976;73-100.

20. Freeman HJ. Role of biopsy in diagnosis and treatment of adult celiac disease. Gastroenterol Hepatol Bed Bench. 2018;11:191-196.

21. Bıçak DA, Urgancı N, Akyüz S, Usta M, Kızılkan NU, Alev B, Yarat A. Clinical evaluation of dental enamel defects and oral findings in coeliac children. Eur Oral Res. 2018; 52:150-156.

22. Aine L, Mäki M Reunala T. Coeliac-type dental enamel defects in patients with dermatitis herpetiformis. Acta Derm Venereol. 1992;72:25-27.

23. Cervino G, Fiorillo L, Laino L, Herford A, Lauritano F, Giudice G. et al. Oral Health Impact Profile in Celiac Patients: Analysis of Recent Findings in a Literature Review. Gastroenterol Res Pract. 2018, Article ID 7848735.

24. Fraser D Nikiforuk G. The etiology of enamel hypoplasia in children - a unifying concept. J Int Assoc Dent Child. 1982;13:1-11.

25. Pastore L, Campisi G, Compilato D. and Lo Muzio L. Orally based diagnosis of celiac disease: current perspectives. J Dent Res. 2008;87:1100-1107.

26. Sóñora $\mathrm{C}$, Arbildi P, Rodríguez-Camejo C, Beovide V, Marco A, Hernández A. Enamel organ proteins as targets for antibodies in celiac disease: implications for oral health. Eur J Oral Sci. 2016;124:11-6.

27. Fejerskove O, Thylstrup A. Different concepts of dental caries and their implications. In: Textbook of clinical cariology edt. By Thylstrup A, Fejerskov O. $2^{\text {nd }}$ Ed. Munksgarrd, Copenhagen, 1994:209-217.

28. Yassin HN. Comparison of immunoglobulin $\operatorname{IgA}$ level in the stimulated saliva of caries-free and caries-active children aged 7-10 years. J Bagh Coll Dent. 2016;38:155-158.

29. Radhi NJ, Alfayad DW. Salivary Immunoglobulin (A, G and M) in Relation to Dental Caries among Group of Kindergartens Children. Int J Sci Technol. 2012;143:1-4.

30. Taaheri J, Bakhashi M, Aryanki A, Noormohammadi R. Use of Saliva for Diagnosis of Diseases. JIDAI. 2014;26:55-66. 
الخلفية: إن مرض مناعي ذاتي كداء الحنطة يؤثر على صحة الأمعاء لدى الإنسان و ينعكس على صحة جسمه بشكل كامل عن طريق سوء

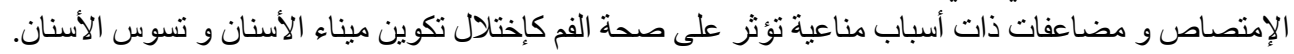

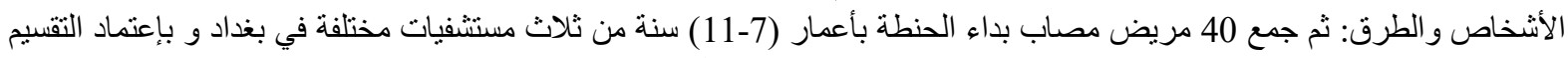

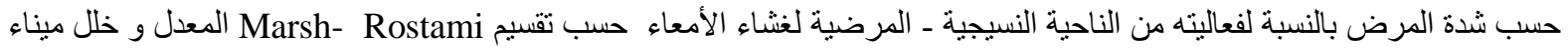
الأسنان عن طريق تقسيم Aine الخاص بداء الحنطة كذلك تجربة تسوس الأسنان وشدتهاء النهاء

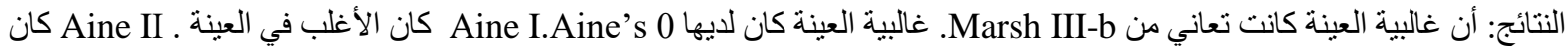

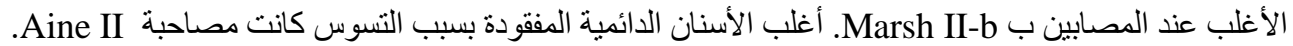

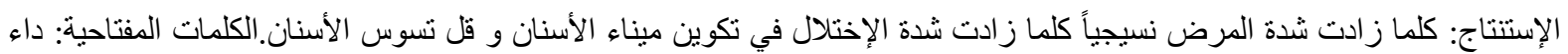

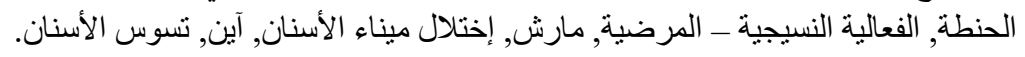

